\title{
AN EXAMINATION OF THE PROFESSIONAL IDENTITY, WORK ENGAGEMENT, AND JOB SATISFACTION \\ OF HIGHER EDUCATION STAFF MEMBERS
}

\author{
Jill Marie Hermsen \\ Dr. Vicki Rosser, Dissertation Supervisor
}

\begin{abstract}
Staff members are a large and growing set of employees within higher education (U.S. Department of Education, 2008). This growth coincides with increased public concern about higher education, which has affected salaries and working conditions (Johnsrud, 2002). Despite these changes, limited research exists on the work lives of higher education staff members. The purpose of this study is to explore the relationships among staff members' work life perspectives, identity issues, demographic and profile characteristics, work engagement, and job satisfaction. The conceptual framework drew upon work engagement (Kahn, 1990) and job satisfaction (Rosser, 2004) literature.

The results of the study were based on 178 responses to a survey instrument administered to staff members working at a Midwestern, public, research university (Carnegie, n.d.). Data analysis included using descriptive statistics, t-tests, ANOVAs, correlation coefficients, Principal Components Analysis, and multiple regression analysis. Results indicated that staff members were positive about their work relations yet less positive about their working conditions and networks but differences existed in responses by some demographic and profile characteristics. Furthermore, work engagement and job satisfaction were distinct but related constructs that were explained by both work life and identity indicators. The findings shed light on the factors that explain the work engagement and job satisfaction of higher education staff members.
\end{abstract}

